\title{
Prognostic impact of platinum sensitivity in ovarian carcinoma patients with brain metastasis
}

\author{
Alexandre André Balieiro Anastácio da Costa $^{1 *}$ D, Elizabeth Santana dos Santos ${ }^{1}$, Deborah Porto Cotrim , \\ Natasha Carvalho Pandolfi', Marcelle Goldner Cesca ${ }^{1}$, Henrique Mantoan², Solange Moraes Sanches', \\ Adriana Regina Gonçalves Ribeiro', Louise de Brot ${ }^{3}$, Graziele Bonvolim³ , Paulo Issamu Sanematsu4, \\ Ronaldo Pereira de Souza', Joyce Maria Lisboa Maya ${ }^{1}$, Fabrício de Souza Castro', \\ João Paulo da Nogueira Silveira Lima', Michael Jenwel Chen ${ }^{5}$, Andrea Paiva Gadelha Guimarães ${ }^{1}$ and \\ Glauco Baiocchi ${ }^{2}$
}

\begin{abstract}
Background: Brain metastasis (BM) is a rare event in ovarian cancer patients. The current prognostic scores that have been used for other tumors do not account for specific characteristics of ovarian cancer, such as platinum sensitivity.

Methods: This retrospective cohort study examined patients with ovarian carcinoma and BM who were treated at a single institution from January 2007 to December 2017. Clinical data on the diagnosis of BM and follow-up were collected. Cox regression was used to evaluate prognostic factors for overall survival (OS).

Results: Of 560 patients, 26 presented with BM. Eight patients were treated with surgery, 15 with whole-brain radiotherapy (RT), and 5 with stereotactic RT, and 4 patients received systemic treatment at the diagnosis of BM. The median OS was 10.8 months. The following factors were associated with OS: platinum-sensitive recurrence (HR $0.34,95 \% \mathrm{Cl} 0.12-0.99 ; p=0.049$ ), higher number of previous treatment lines (HR 1.57,95\% Cl 1.12-2.19; $p=0.008$ ), ECOG performance status (HR 2.52,95\% Cl 1.24-5.09; $p=0.010$ ), and longer interval from initial diagnosis to BM $(p=0.025)$. Notably, the number of brain metastasis, the largest tumor size, and progression outside of the CNS were not related to survival. Platinum sensitivity was not associated with any of the classic prognostic factors in brain metastasis patients such as number or size of brain metastasis or disease progression outside the CNS strengthening the hypothesis of the importance of platinum sensitivity to the prognosis of ovarian cancer patients with BM.

Conclusions: The factors related to the biological behavior of the ovarian cancer such as platinum sensitivity at the time of BM diagnosis, fewer number of previous treatment lines and interval from initial diagnosis were associated with survival in ovarian cancer patients with BM, while factors that are usually related to survival in BM in other cancers were not associated with survival in this cohort of ovarian cancer patients. The small number of patients did not allow us to exclude the prognostic role of these former factors that were not associated with survival in the present cohort.
\end{abstract}

Keywords: Brain metastasis, Prognostic factors, Ovarian cancer, Platinum sensitivity

\footnotetext{
* Correspondence: lexandreandredacosta@gmail.com

${ }^{1}$ Medical Oncology Department, A.C. Camargo Cancer Center, 211 Professor

Antonio Prudente Street, Liberdade, São Paulo, SP 01509-900, Brazil

Full list of author information is available at the end of the article
}

(c) The Author(s). 2019 Open Access This article is distributed under the terms of the Creative Commons Attribution 4.0 International License (http://creativecommons.org/licenses/by/4.0/), which permits unrestricted use, distribution, and reproduction in any medium, provided you give appropriate credit to the original author(s) and the source, provide a link to the Creative Commons license, and indicate if changes were made. The Creative Commons Public Domain Dedication waiver (http://creativecommons.org/publicdomain/zero/1.0/) applies to the data made available in this article, unless otherwise stated. 


\section{Background}

Ovarian cancer is the eighth most frequent cancer among women, amounting to 295,414 cases worldwide in 2018 [1]. It is the most lethal gynecological cancer, accounting for $2.5 \%$ of female malignancies but $5.0 \%$ of deaths due to cancer in women [2]. Brain metastasis $(\mathrm{BM})$ is an uncommon event in ovarian cancer patients and is estimated to occur in 0.3 to $12 \%$ of patients, depending on the series. The highest frequencies have been seen in more recent series, likely due to the advent of more accurate diagnostic tools and longer survival in this era of new treatment options [3].

$\mathrm{BM}$ can be treated with various combinations of surgery, whole-brain radiotherapy, and stereotactic radiotherapy. Combination of surgery and radiotherapy yields better survival than single modality treatment alone, and the prognosis is a key component of the treatment decision, surgery usually reserved for patients with 1 to 3 lesions, controlled systemic disease and good performance status [4]. The response to systemic treatment including chemotherapy or targeted therapy in the BM seems to parallel the response of the primary tumor [4].

Classical prognostic scores as the RTOG Recursive Partitioning Analysis (RPA), and the grade prognostic index (GPA) have mainly accounted for primary tumors with the highest frequencies of BM, such as melanoma and lung, breast, and kidney cancer $[5,6]$. Aiming to refine the prognostic evaluation for specific primary tumor sites the Disease-Specific Grade Prognostic Index (DS-GPA) was developed, for which only melanoma, lung, breast, kidney, and gastrointestinal cancer have been studied [7]. In the classical non-disease specific scores and in the scores for most studied primary sites, age, KPS, extracranial metastases, and the number of BMs are relevant prognostic factors [5-7].

Due to its rarity, BM from ovarian carcinoma is underrepresented in these studies. BM from ovarian carcinoma has been lumped with other primary gynecological tumors [8-12] and in small series of ovarian carcinoma cases [13-18]. Only 2 recent series presented more than 40 ovarian carcinoma patients with $\mathrm{BM}[13,15]$. In these series the prognostic factors most often associated with survival were performance status, size and number of brain metastasis [8-18]. Only three of these series evaluated platinum sensitivity at the time of BM diagnosis as prognostic factors for survival $[13,15,16]$.

In this study, we evaluated prognostic factors in a cohort of ovarian cancer patients who presented with BM, considering the specific characteristics of ovarian cancer treatment and its natural history.

\section{Methods}

\section{Patients}

This retrospective cohort study comprised all consecutive patients with ovarian carcinoma who were treated at
A.C. Camargo Cancer Center from January 2007 to December 2017, irrespective of the date of diagnosis, and who developed brain metastasis (BM).

The study was conducted in accordance with the Declaration of Helsinki ethical guidelines and approved by the institutional Ethics Committee (CEP\# 2649/18).

\section{Clinical data}

Clinical findings were retrieved from the medical records. Baseline characteristics included the date of diagnosis, age at diagnosis of ovarian cancer, tumor histological subtype, staging, residual disease after debulking surgery, and personal history of ovarian and breast cancer. Clinical characteristics at the time of the diagnosis of BM included: type of recurrence regarding platinum sensitivity, number of previous chemotherapy treatment lines, sites of metastatic disease, status of extra-nervous system disease progression, number of BMs, size of largest BM, platinum-free interval, and time from diagnosis. Data on treatment modality at the time of BM were also retrieved.

Recurrence was defined per the GCIG (Gynecological Cancer Intergroup) criteria for CA125 progression or per RECIST (Response Evaluation Criteria in Solid Tumors) for image studies obtained from the medical records. The date of the earliest event was considered for progression [19, 20]. Recurrence that was detected after 6 months of the last platinum infusion was defined as platinum-sensitive recurrence, whereas that within 6 months was considered platinum-resistant recurrence. All recurrences that followed the initial platinumresistant recurrence were also considered to be platinum-resistant. Overall survival was defined as the interval between the date of the diagnosis of $\mathrm{BM}$ and death due to any cause. The interval between the date of the last platinum compound infusion and the date of the diagnosis of BM was defined as the platinum-free interval (PFI).

\section{Statistical analysis}

Frequencies, medians, and interquartile range (IQR) were used to describe the patients' characteristics. The association between clinical characteristics was tested by Qui-square Test or Fisher's Exact test when necessary. Overall survival curves were plotted by Kaplan-Meier method and we used log-rank test to test the association between clinical characteristics and overall survival. Hazard ratios were calculated by Cox regression analysis, but due to the small number of patients, only univariate analysis was performed.

When necessary, continuous variables were dichotomized using the medium value of the cohort as the cutoff. The statistical analysis was performed using SPSS v. 
21.0 (SPSS, Chicago, IL, US), adopting a two-tailed $p$ value $<0.05$ as significant.

\section{Results}

Of the 560 patients with ovarian carcinoma treated at A.C. Camargo Cancer Center from January 2007 to December 2017, 26 (4.6\%) developed BM during the follow-up. The median age at the diagnosis of BM was 63.0 years, and the median time from the primary diagnosis to BM was 31.7 months; most patients presented with high-grade serous carcinoma and had a negative family history for breast or ovarian cancer and an ECOG performance status of 0 or 1 (Table 1 ).

Approximately $50 \%$ of the patients experienced a recurrence that was classified as platinum-sensitive, $46.2 \%$ was treated with just one previous line of chemotherapy, and $57.4 \%$ did not have concurrent disease progression outside of the central nervous system, and in 6 (23.2\%)

Table 1 Clinical characteristics of the 26 ovarian cancer patients with brain metastasis

\begin{tabular}{|c|c|}
\hline Characteristic & Freq. (\%) \\
\hline Age (median / IQR) & $63.0(54.1-65.7)$ \\
\hline \multicolumn{2}{|l|}{ Family history } \\
\hline Present & $5(19.2)$ \\
\hline Absent & $19(73.1)$ \\
\hline Unknown & $2(7.7)$ \\
\hline \multicolumn{2}{|l|}{ Histology } \\
\hline High grade serous & $17(65.4)$ \\
\hline Endometrioid & $2(7.7)$ \\
\hline Undifferentiated & $2(7.7)$ \\
\hline Carcinossarcoma & $1(3.8)$ \\
\hline Mixed & $1(3.8)$ \\
\hline Unknown & $3(11.5)$ \\
\hline \multicolumn{2}{|l|}{ FIGO stage } \\
\hline$|-|||$ & $20(76.9)$ \\
\hline IV & $5(19.2)$ \\
\hline Unknown & $1(3.8)$ \\
\hline \multicolumn{2}{|c|}{ ECOG performance status } \\
\hline 0 & $4(15.4)$ \\
\hline 1 & $12(46.2)$ \\
\hline 2 & $2(7.7)$ \\
\hline 3 & $3(11.5)$ \\
\hline Unknown & $5(19.2)$ \\
\hline \multicolumn{2}{|c|}{ Residue disease after first surgery } \\
\hline$>1 \mathrm{~cm}$ & $18(69.2)$ \\
\hline$<1 \mathrm{~cm}$ & $5(19.2)$ \\
\hline Unknown & $3(11.5)$ \\
\hline
\end{tabular}

IQR Interquartile range, FIGO International Federation of Gynecology and Obstetrics, ECOG Eastern Cooperative Oncology Group of these patients BM was the only site of metastatic disease. The number of BMs varied widely, and one-third of patients presented with a single BM, compared with one-fourth who developed multiple ( $>20$ ) BMs. The median size of the BMs was $3.2 \mathrm{~cm}$. Roughly $80 \%$ of patients were treated with radiotherapy; 8 patients $(20.8 \%)$ underwent surgery, all of whom were administered whole-brain radiotherapy or stereotaxic radiotherapy afterward (Table 2).

\section{Overall survival}

At a median follow-up of 18.7 months since the diagnosis of BM, the median overall survival was 10.8 months (Fig. 1). Of the 18 patients who died, the cause of death was related to BM in 13 patients (72.2\%). For the other 5 patients who died the cause of death was: bowel obstruction due to peritoneal carcinomatosis in two patients, respiratory failure due to lung metastasis in one

Table 2 Characteristics of CNS metastasis

\begin{tabular}{ll}
\hline Characteristic & Freq. (\%) \\
\hline Time-point of CNS metastasis & $14(53.8)$ \\
Platinum sensitive & $11(42.3)$ \\
Platinum resistant & $1(3.8)$ \\
Unknown & \\
Previous CT lines before diagnosis CNS metastasis & $12(46.2)$ \\
1 & $2(7.7)$ \\
2 & $3(11.5)$ \\
3 & $5(19.2)$ \\
4 & $3(11.5)$ \\
5 & $1(3.8)$ \\
Unknown & \\
BM as only site of metastatic disease & $6(23.2)$ \\
Yes & $20(76.9)$ \\
No & \\
Extra-CNS disease progression & $11(42.6)$ \\
Yes & $14(53.8)$ \\
No & $1(3.8)$ \\
Unknown & $4.5(1-20)$ \\
Number of metastasis (median /IQR) & $3.2(2.1-3.7)$ \\
Metastasis size (median/IQR) & $10.9(4.2-22.4)$ \\
Time from diagnosis (median/IQR) & $31.8(18.9-55.8)$ \\
Sureatment & \\
WBRT & $5(15.4)$ \\
\hline CNS & \\
SRT & \\
\hline
\end{tabular}

CNS Central nervous system, CT Chemotherapy, IQR Interquartile range, WBRT Whole brain radiotherapy, SRT Stereotaxic radiotherapy 


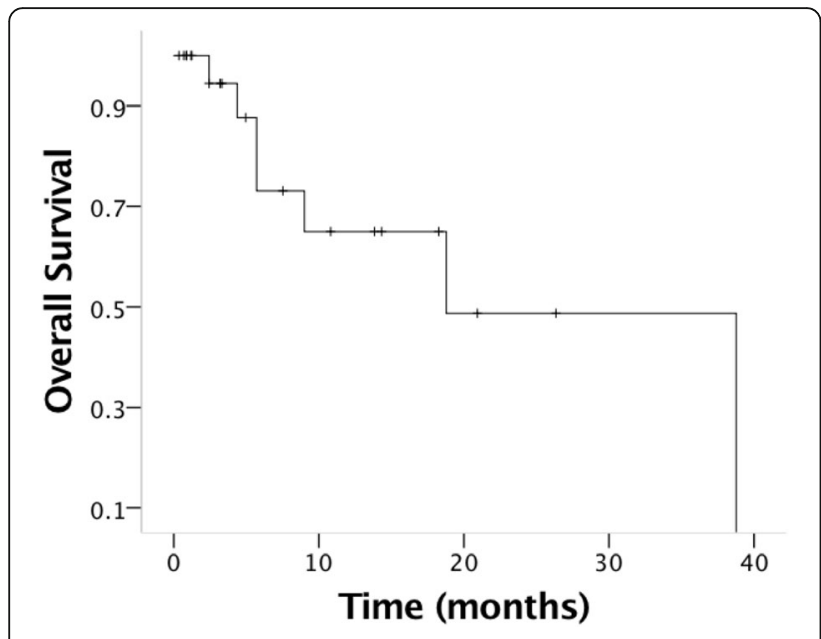

Fig. 1 Overall survival for the 26 patients with brain metastasis from ovarian carcinoma. The median overall survival was 18.8 months

patient and pleural metastasis in another patient, and cholangitis due to liver metastasis in one patient. The following factors were associated with overall survival: platinum-sensitive recurrence (HR 0.34, 9y5\% CI 0.12 $0.99 ; p=0.049)$, higher number of previous treatment lines (HR 1.57, 95\% CI 1.12-2.19; $p=0.008$ ), and ECOG performance status (HR 2.52, 95\% CI 1.24-5.09; $p=$ 0.010) (Fig. 2 and Table 3).
Using median values as cutoffs for continuous variables, the time from diagnosis was associated with overall survival (HR 3.27, 95\% CI 1.10-9.71, $p=0.033$ ), and patients with 4 or fewer BMs had better overall survival compared with those with 5 or more BMs (HR 2.91, 95\% CI $0.95-8.99 ; p=0.063)$. Median tumor size larger than $3.2 \mathrm{~cm}$ (HR 1.02, 95\% CI 0.338-3.05, $p=0.979$ ), and progression outside of the CNS (HR 0.52, 95\% CI 0.18-1.53, $p=0.236$ ) were not associated with survival (Fig. 3 and Table 3).

\section{Association of platinum sensitivity and characteristics of brain metastasis}

In order to evaluate if the association of platinum sensitivity with survival was due to a confounder effect of its association with the classic prognostic factors, we evaluated the association of platinum sensitivity with other clinical characteristics.

Residual disease after the initial surgery (primary debulking or interval debulking surgery) that exceeded 1 $\mathrm{cm}$ was related to the diagnosis of BM in the platinumresistant setting. All 5 patients with residual disease $>1$ $\mathrm{cm}$ had a diagnosis of $\mathrm{BM}$ in the platinum-resistant setting $(p=0.014)$. A diagnosis of $\mathrm{BM}$ after 3 or more chemotherapy treatment lines was also associated with platinum resistance, 11 of 14 patients with less than 3 previous treatment lines had platinum sensitive

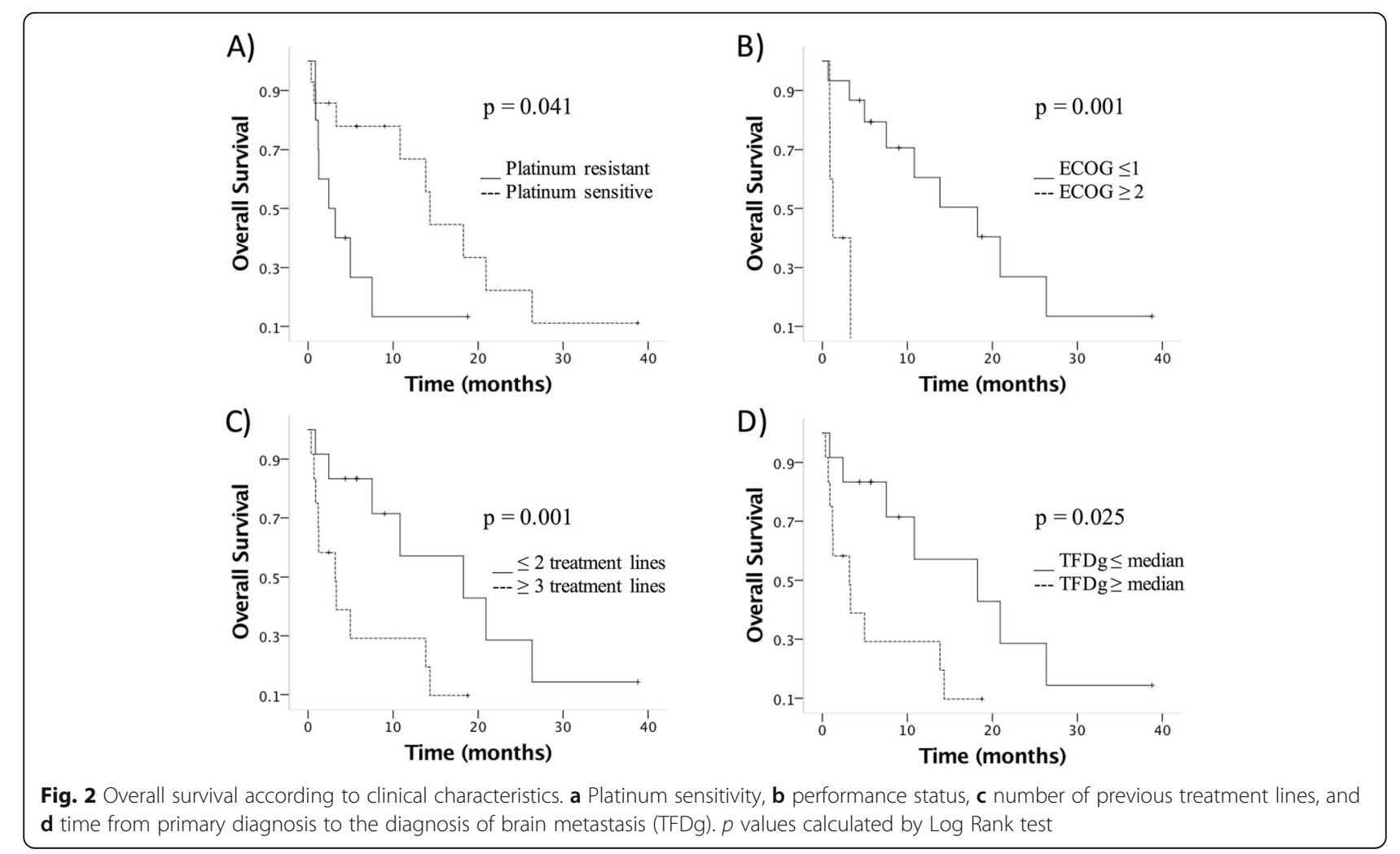


Table 3 Univariate analysis for Overall Survival

\begin{tabular}{|c|c|c|}
\hline Characteristic & $\mathrm{HR}(95 \% \mathrm{Cl})$ & $p$ value \\
\hline$\overline{\mathrm{Age}^{\mathrm{a}}}$ & $1.02(0.96-1.08)$ & 0.493 \\
\hline ECOG performance status $^{\mathrm{a}}$ & $2.52(1.25-5.09)$ & 0.010 \\
\hline \multicolumn{3}{|l|}{ Family History of Breast or Ovarian Cancer } \\
\hline No & 1 & 0.593 \\
\hline Yes & $0.73(0.23-2.30)$ & \\
\hline \multicolumn{3}{|l|}{ Histology } \\
\hline HGCS & 1 & 0.747 \\
\hline Other histologies & $0.81(0.22-3.00)$ & \\
\hline \multicolumn{3}{|l|}{ Time-point of CNS metastasis } \\
\hline Platinum sensitive & 1 & 0.049 \\
\hline Platinum resistant & $2.89(1.01-8.31)$ & \\
\hline Previous lines before diagnosis of $\mathrm{BM}^{\mathrm{a}}$ & $1.57(1.12-2.19)$ & 0.008 \\
\hline \multicolumn{3}{|l|}{ Disease progression outside CNS } \\
\hline No & 1 & 0.236 \\
\hline Yes & $0.52(0.18-1.53)$ & \\
\hline Number of metastasis ${ }^{a}$ & $1.06(0.99-1.13)$ & 0.104 \\
\hline Metastasis size ${ }^{a}$ & $0.83(0.49-1.39)$ & 0.473 \\
\hline Time from diagnosis $^{\mathrm{a}}$ & $1.01(1.00-1.01)$ & 0.200 \\
\hline Platinum free interval ${ }^{a}$ & $0.99(0.93-1.05)$ & 0.747 \\
\hline
\end{tabular}

ECOG Eastern Cooperative Oncology Group, HGSC High grade serous carcinoma, CNS Central nervous system

a evaluated as continuous variables recurrence while 3 of 11 patients with more than 3 previous treatment lines had platinum resistant recurrence at the time of diagnosis of BM $(p=0.017)$.

Notably, there was no association between a diagnosis of $\mathrm{BM}$ in the platinum-resistant setting and having 1 versus $>1$ metastasis $(p=0.423)$, $\mathrm{BM}$ larger than $3.2 \mathrm{~cm}$ (median for the cohort) $(p=0.650)$, or concurrent disease progression outside of the central nervous system $(p=1.00)$. Moreover, the number of deaths that were attributable to BM was similar in patients who were diagnosed with $\mathrm{BM}$ in the platinum-resistant and platinumsensitive settings -3 of $5(60.0 \%)$ and 6 of $13(46.2 \%)$, respectively $(p=1.00)$.

Other factors such as family history of breast or ovarian cancer $(p=1.00)$, high grade serous carcinoma histology $(p=1.00)$ and FIGO stage $(p=1.00)$ were also not associated with platinum sensitivity at the time of $\mathrm{BM}$ diagnosis (Table 4).

\section{Discussion}

$\mathrm{BM}$ from ovarian cancer is a rare but severe event in the course of the disease. In this study, of 560 ovarian cancer patients, we evaluated data on 26 patients who developed BM. Their overall survival was poor, with a median overall survival of 10.8 months, and $72 \%$ of them died due to the BM. Performance status, a diagnosis of BM in the platinum-resistant setting, the time from the initial diagnosis to that of $\mathrm{BM}$, and the number of previous treatment lines correlated with shorter survival. Notably, the number and size of BMs and the presence of disease

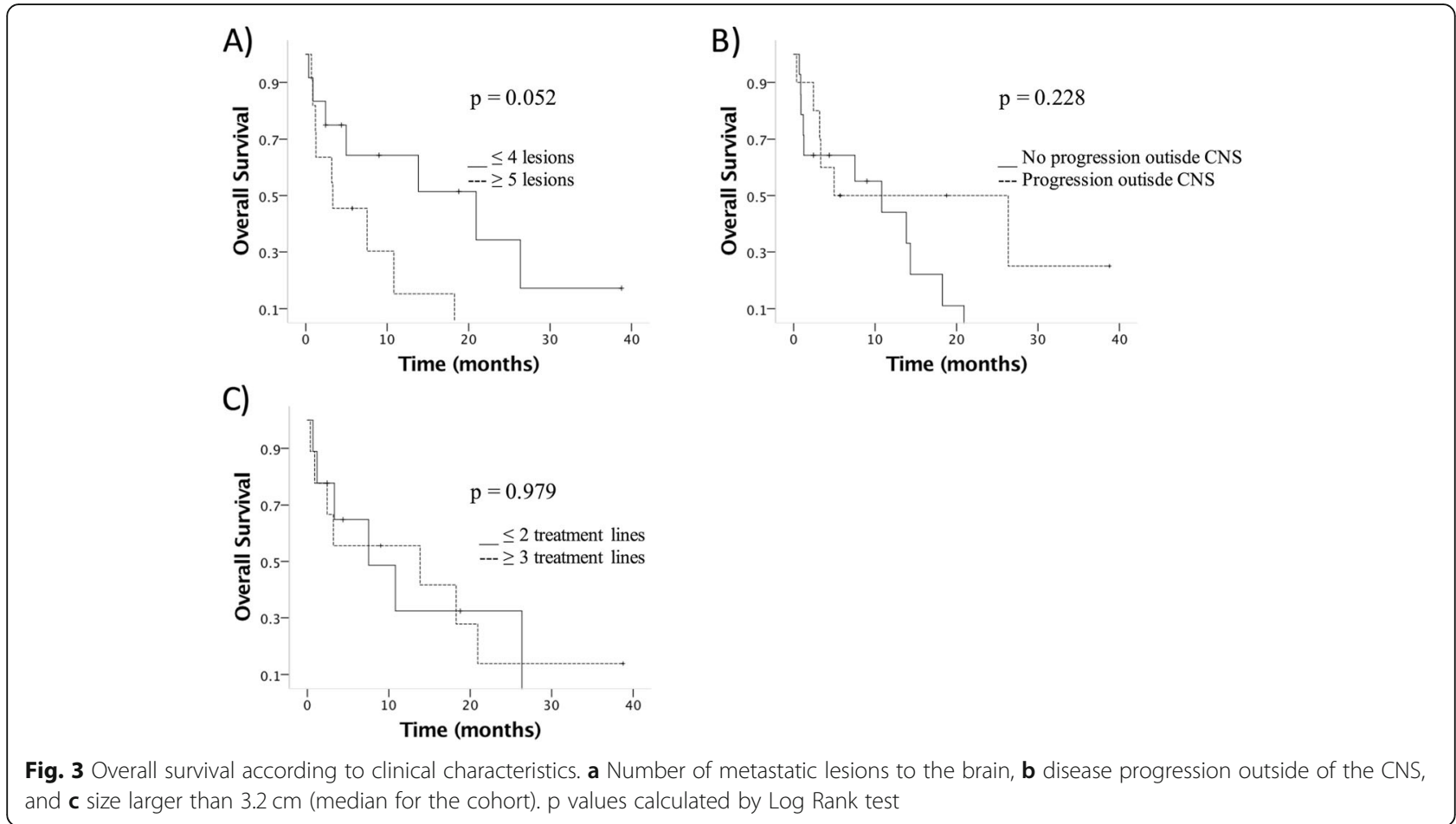


Table 4 Association of clinical characteristics and platinum sensitivity

\begin{tabular}{|c|c|c|c|}
\hline \multirow[t]{2}{*}{ Characteristic } & Platinum-sensitivity & Platinum-resistance & $p^{*}$ \\
\hline & Frequency (\%) & Frequency (\%) & \\
\hline \multicolumn{4}{|c|}{ Family History of Breast or Ovarian Cancer } \\
\hline No & $10(55.6)$ & $8(44.4)$ & 1.000 \\
\hline Yes & $3(60.0)$ & $2(40.0)$ & \\
\hline \multicolumn{4}{|l|}{ Histology } \\
\hline HGCS & $10(52.6)$ & $9(47.4)$ & 1.000 \\
\hline Other histologies & $2(66.7)$ & $1(33.3)$ & \\
\hline \multicolumn{4}{|l|}{ FIGO stage } \\
\hline$|-|||$ & $11(55.0)$ & $9(45.0)$ & 1.000 \\
\hline IV & $2(50.0)$ & $2(50.0)$ & \\
\hline \multicolumn{4}{|c|}{ Residual disease after primary surgery } \\
\hline$<1 \mathrm{~cm}$ & $12(66.7)$ & $6(33.3)$ & 0.014 \\
\hline$\geq 1 \mathrm{~cm}$ & $0(0)$ & $5(100)$ & \\
\hline \multicolumn{4}{|c|}{ Disease progression outside CNS } \\
\hline No & $8(57.1)$ & $6(42.9)$ & 1.000 \\
\hline Yes & $6(54.5)$ & $5(45.5)$ & \\
\hline \multicolumn{4}{|l|}{ Number of metastasis } \\
\hline 1 & $6(66.7)$ & $3(33.3)$ & 0.423 \\
\hline$>1$ & $7(46.7)$ & $8(53.3)$ & \\
\hline \multicolumn{4}{|c|}{ Largest size of brain metastasis } \\
\hline$<3.2 \mathrm{~cm}$ (median) & $5(50.0)$ & $5(50.0)$ & 0.650 \\
\hline$\geq 3.2 \mathrm{~cm}$ (median) & $6(66.7)$ & $3(33.3)$ & \\
\hline \multicolumn{4}{|c|}{ Number of previous lines of $\mathrm{CT}$} \\
\hline$<3$ & $11(78.6)$ & $3(21.4)$ & 0.017 \\
\hline$s \geq 3$ & $3(27.3)$ & $8(72.7)$ & \\
\hline \multicolumn{4}{|c|}{ Death directly related to BM } \\
\hline No & $2(40.0)$ & $3(60.0)$ & 1.000 \\
\hline Yes & $7(53.8)$ & $6(46.2)$ & \\
\hline
\end{tabular}

HGSC High grade serous carcinoma, CNS Central nervous system, BM Brain metastasis * $p$ values calculated with Exact Fisher's test

outside of the central nervous system were unrelated to survival.

A poor median overall survival from the diagnosis of $\mathrm{BM}$ has been observed in other series. The 2 largest previous series and 1 systematic review reported a median overall survival of 6.2 months, [13] 8.2 months, [3] and 12.0 months, [15] respectively. The impact of $\mathrm{BM}$ on survival could be underestimated if it is mistaken for a late event in patients toward the end of life who die from other mechanisms that are related to systemic disease. In our study, $72.2 \%$ of deaths were directly attributable to $\mathrm{BM}$, and $57.4 \%$ did not have concurrent disease progression outside of the central nervous system; these rates did not differ between patients with platinumsensitive and platinum-resistant recurrence. An earlier study that evaluated the prognostic impact of various sites of recurrence in ovarian cancer showed that patients with BMs have the worst prognosis [21]. Collectively, these data suggest that $\mathrm{BM}$ is not an indirect marker of late-stage disease but is instead a direct mechanism of death in most ovarian cancer patients with BM.

Platinum-free interval is one of the most important prognostic factors in the recurrence of ovarian cancer [22]. Most previous series of patients with BM from ovarian cancer did not consider this specific characteristic of ovarian cancer patients. Sehouli et al. screened 4077 ovarian cancer patients to find 74 patients with $\mathrm{BM}$ and showed that a diagnosis of BM in the platinumsensitive setting was associated with better survival, with an HR of 0.23 [13]. Liu et al. analyzed 29 patients and also noted a correlation between platinum sensitivity and overall survival, wherein patients who experienced platinum-resistant recurrence had a 5.13-fold greater chance of death [16]. The more recent and larger MITO study evaluated platinum sensitivity as a prognostic marker and found no link between platinum sensitivity and the prognosis [15]. However, it defined platinum sensitivity based on the platinum-free interval of the first recurrence, whereas our study, Sehouli et al., and Liu et al. classified platinum sensitivity, based on the platinum-free interval at the time of the diagnosis of the BM $[13,16]$. Among published series these three studies were the only ones that reported the prognostic impact of PFI in the moment of BM diagnosis, and the last one from the MITO group used a different definition of platinum sensitivity. With our study we add data on the importance of PFI in the decision-making process in this scenario.

A higher number of previous treatment lines and a longer interval since the primary diagnosis to the diagnosis of BM were associated with a shorter survival. These findings highlight the importance of the behavior of the disease with regard to the prognosis, because patients with more treatment lines and a longer period since the primary diagnosis are at greater risk of platinum-resistant recurrence. In our study, patients with 3 or more previous treatment lines had a higher likelihood of platinum-resistant recurrence. Although the time from the primary diagnosis has been evaluated in other series, with varying results, $[17,18]$ the number of previous treatment lines has not been examined.

Among the classical prognostic factors for survival in patients with $\mathrm{BM}[5,6]$, only performance status was relevant in our study. Age, disease progression outside of the central nervous system, and the number and size of BMs have been linked to overall survival in previous studies $[3,13-15,18]$ but were unrelated to overall survival in our cohort. None of these factors was related to platinum sensitivity at the time of BM, arguing against platinum sensitivity as a confounding factor. 
We did not have data on $B R C A$ status for our patients, but 7 studies have reported these data for 37 patients with BM. Among them, 21 patients carried a pathogenic $B R C A$ mutation $[13,23-25]$. There are no data for ovarian cancer patients with $\mathrm{BM}$ regarding the prognostic impact of $B R C A$ mutations. Disease-specific prognostic scores for breast [7] and lung cancer [26] have already incorporated molecular subtypes and driver mutations. This deficiency is a limitation of our and previous reports on ovarian cancer and should be considered in future studies.

Other study limitations are due primarily to the small number of patients, limiting the multivariate analysis what does not allow us to completely exclude the possibility of confounding factors leading to the results seen in univariate analysis, and generating low statistical power in excluding the importance of prognostic factors that are otherwise not associated with survival. However, considering the rarity of BM in ovarian cancer patients, this series has yielded significant data, recognizing the factors that are specific to ovarian cancer patients, such as platinum sensitivity and multiple lines of treatment.

\section{Conclusions}

In conclusion, the factors that are related to platinum sensitivity and BM as an early event during the course of the disease appear to be more related to survival than the classical factors that are usually associated with survival in BM from other cancers.

\section{Abbreviations}

BM: Brain Metastasis; CNS: Central nervous system; DS-GPA: Disease-Specific Grade Prognostic Index; ECOG: Eastern Cooperative Oncology Group; GCIG: Gynecological Cancer Intergroup; HR: Hazard ratio; IQR: Interquartile range; KPS: Karnofsky performance status; OS: Overall survival; PFI: Platinumfree interval; RECIST: Response Evaluation Criteria in Solid Tumors; $\mathrm{RT}$ : Radiotherapy

\section{Acknowledgements}

Not applicable.

\section{Authors' contributions \\ $A A B A d C, E S d S$ and $G B$ were involved in the conception and design of the work; DPC, NCP, MGC, HM, ARGR, LB, GB, PIS, RPdS, JMLM, FdSC, MJC and GB contributed with data acquisition, $A A B A d C$ performed the statistical analyses, AABAdC, ESdS, MJC, SMS, ARGR, LB, GB, JPdNSL, MJC, APGG and GB contributed with data interpretation, all authors were involved in drafting the work and revising it critically for important intellectual content. All authors read and approved the final manuscript. \\ Funding \\ We had no financial support.}

\section{Availability of data and materials}

The datasets used and/or analyzed during the current study are available from the corresponding author on reasonable request.

\section{Ethics approval and consent to participate}

The A.C. Camargo Cancer Center Ethics Committee approved the study (CEP\# 2649/18). The need for informed consent has been waived by the A.C. Camargo Cancer Center Ethics Committee.
Consent for publication

Not applicable.

\section{Competing interests}

The authors declare that they have no competing interests.

\section{Author details}

${ }^{1}$ Medical Oncology Department, A.C. Camargo Cancer Center, 211 Professor Antonio Prudente Street, Liberdade, São Paulo, SP 01509-900, Brazil.

${ }^{2}$ Gynecology Oncology Department, A.C. Camargo Cancer Center, 211

Professor Antonio Prudente Street, Liberdade, São Paulo, SP 01509-900, Brazil.

${ }^{3}$ Pathology Department, A.C. Camargo Cancer Center, 211 Professor Antonio

Prudente Street, Liberdade, São Paulo, SP 01509-900, Brazil. ${ }^{4}$ Neurosurgery

Department, A.C. Camargo Cancer Center, 211 Professor Antonio Prudente

Street, Liberdade, São Paulo, SP 01509-900, Brazil. ${ }^{5}$ Radiotherapy Department, A.C. Camargo Cancer Center, 211 Professor Antonio Prudente Street,

Liberdade, São Paulo, SP 01509-900, Brazil.

Received: 14 March 2019 Accepted: 20 November 2019

Published online: 05 December 2019

\section{References}

1. Bray F, Ferlay J, Soerjomataram I, Siegel RL, Torre LA, Jemal A. Global cancer statistics 2018: GLOBOCAN estimates of incidence and mortality worldwide for 36 cancers in 185 countries. Cancer J Clin. 2018;49(suppl 8):509-31.

2. Torre LA, Trabert B, DeSantis CE, et al. Ovarian cancer statistics, 2018. Cancer J Clin. 2018;68(4):284-96.

3. Pakneshan S, Safarpour D, Tavassoli F, Jabbari B. Brain metastasis from ovarian cancer: a systematic review. J Neuro-Oncol. 2014;119(1):1-6.

4. Soffietti $R$, Abacioglu U, Baumert B, et al. Diagnosis and treatment of brain metastases from solid tumors: guidelines from the European Association of Neuro-Oncology (EANO). Neuro-Oncol. 2017;19(2):162-74.

5. Gaspar LE, Scott C, Murray K, Curran W. Validation of the RTOG recursive partitioning analysis (RPA) classification for brain metastases. Int J Radiat Oncol Biol Phys. 2000;47(4):1001-6.

6. Sperduto PW, Berkey B, Gaspar LE, Mehta M, Curran W. A new prognostic index and comparison to three other indices for patients with brain metastases: an analysis of 1,960 patients in the RTOG database. Int J Radiat Oncol Biol Phys. 2008;70(2):510-4

7. Sperduto PW, Kased N, Roberge D, et al. Summary report on the graded prognostic assessment: an accurate and facile diagnosis-specific tool to estimate survival for patients with brain metastases. J Clin Oncol. 2012;30(4): 419-25.

8. Kim YZ, Kwon JH, Lim S. A clinical analysis of brain metastasis in gynecologic Cancer: a retrospective multi-institute analysis. J Korean Med Sci. 2015;30(1):66-8.

9. Shin HK, Kim JH, Lee DH, Cho YH, Kwon DH, Roh SW. Clinical outcomes of gamma knife radiosurgery for metastatic brain tumors from gynecologic Cancer : prognostic factors in local treatment failure and survival. J Korean Neurosurg Soc. 2016;59(4):392-8.

10. Nasu K, Satoh T, Nishio $S$, et al. Clinicopathologic features of brain metastases from gynecologic malignancies: a retrospective study of 139 cases (KCOG-G1001s trial). Gynecol Oncol. 2013;128(2):198-203.

11. Gressel GM, Lundsberg LS, Altwerger $G$, et al. Factors predictive of improved survival in patients with brain metastases from gynecologic Cancer. Int J Gynecol Cancer. 2015;25(9):1711-6.

12. Takeshita S, Todo Y, Furuta $Y$, et al. Prognostic factors for patients with brain metastasis from gynecological cancer: a significance of treatment-free interval of more than 6 months. Jap J Clin Oncol. 2017;47(7):604-10.

13. Sehouli J, Pietzner $K$, Harter $P$, et al. Prognostic role of platinum sensitivity in patients with brain metastases from ovarian cancer: results of a German multicenter study. Ann Oncol. 2010;21(11):2201-5.

14. Seber S, Turkmen E, Harputoglu H, et al. Central nervous system metastatic epithelial ovarian cancer. Clinical parameters and prognostic factors: a multicenter study of Anatolian Society of Medical Oncology. Eur J Gynaecol Oncol. 2017;38(2):227-31

15. Marchetti C, Ferrandina G, Cormio G, et al. Brain metastases in patients with EOC: Clinico-pathological and prognostic factors. A multicentric retrospective analysis from the MITO group (MITO 19). Gynecol Oncol. 2016; 143(3):532-8. 
16. Liu B-L, Liu S-U, Baskys A, et al. Platinum sensitivity and CD133 expression as risk and prognostic predictors of central nervous system metastases in patients with epithelial ovarian cancer. BMC Cancer. 2014;14:829.

17. Cormio G, Loizzi V, Falagario M, Lissoni AA, Resta L, Selvaggi LE. Changes in the management and outcome of central nervous system involvement from ovarian cancer since 1994. Int J Gynecol Obstet. 2011;114(2):133-6.

18. Ratner ES, Toy E, O'Malley DM, et al. Brain metastases in epithelial ovarian and primary peritoneal carcinoma. Int J Gynecol Cancer. 2009;19(5):856-9.

19. Rustin GJS, Quinn M, Thigpen T, et al. Re: new guidelines to evaluate the response to treatment in solid tumors (ovarian Cancer). J Natl Cancer Inst. 2004;96(6):487-8.

20. Vergote I, Rustin GJS, Eisenhauer EA, et al. Re: new guidelines to evaluate the response to treatment in solid tumors [ovarian Cancer]. J Natl Cancer Inst. 2000;92(18):1534-5.

21. Deng K, Yang C, Tan Q, et al. Sites of distant metastases and overall survival in ovarian cancer: a study of 1481 patients. Gynecol Oncol. 2016;143(3):532-8.

22. Lee CK, Simes RJ, Brown C, et al. A prognostic nomogram to predict overall survival in patients with platinum-sensitive recurrent ovarian cancer. Ann Oncol. 2012;24(4):937-43.

23. Jernigan AM, Mahdi H, Rose PG. Epithelial ovarian Cancer metastatic to the central nervous system and a family history concerning for hereditary breast and ovarian Cancer-a potential relationship. Int J Gynecol Cancer. 2015; 25(7):1232-8.

24. Balendran S, Liebmann-Reindl S, Berghoff AS, et al. Next-generation sequencing-based genomic profiling of brain metastases of primary ovarian cancer identifies high number of BRCA-mutations. J Neuro-Oncol. 2017; 133(3):469-76.

25. Sekine M, Yoshihara K, Komata D, Haino K, Nishino K, Tanaka K. Increased incidence of brain metastases in BRCA1-related ovarian cancers. J Obstet Gynaecol Res. 2012;39(1):292-6.

26. Sperduto PW, Yang TJ, Beal $\mathrm{K}$, et al. Estimating survival in patients with lung Cancer and brain metastases. JAMA Oncol. 2017;3(6):827-5.

\section{Publisher's Note}

Springer Nature remains neutral with regard to jurisdictional claims in published maps and institutional affiliations.

Ready to submit your research? Choose BMC and benefit from:

- fast, convenient online submission

- thorough peer review by experienced researchers in your field

- rapid publication on acceptance

- support for research data, including large and complex data types

- gold Open Access which fosters wider collaboration and increased citations

- maximum visibility for your research: over $100 \mathrm{M}$ website views per year

At $\mathrm{BMC}$, research is always in progress.

Learn more biomedcentral.com/submissions 